\title{
Improving material cutting by application of natural origin oil
}

\author{
Chingiz Yakubov ${ }^{1}$, Ruslan Dzhemalyadinov ${ }^{1, *}$, and Vladimir Skakun ${ }^{1}$ \\ ${ }^{1}$ Crimean Engineering and Pedagogical University, Uchebniy side st.8, 295055 Simferopol, Russian \\ Federation
}

\begin{abstract}
The article deals with the experimental evaluation (in the laboratory) of environmentally secure lubricating and cooling technological means' (LCTM) influence on the force characteristics and tool wear in the turning process of structural materials with different chemical activity. The experiment results confirm that the use of vegetable and animal fats in combination with the minimal quantity lubrication technology (MQL) provides for a significant reduction of cutting forces and the contact area.
\end{abstract}

\section{Problem statement}

The problem of existing LCTM environmental compatibility and their consumption rate reduction (their total contribution reaches $15-20 \%$ at the machine manufacture) sets forth the necessity to search for alternative solutions in relation to the vegetable\&animal oil application combined with the MQL technology. According to the reference data [1], they are included into the LCTM classification. In Germany, the USA and Great Britain the intense works are in progress; their aim is to obtain lubricants on the basis of vegetable oils.

In terms of their lubricating properties vegetable oils are better than petroleum ones and this property offsets their relatively high price $(15 \ldots 20 \%)$. Moreover, the development of the MQL technology with the LCTM consumption decreased by 2 or 3 orders makes this price difference negligeable [2].

\section{Materials and methods of research}

An increased lubricating property of vegetable oils is explained by the fact that the glycerin chemical structure has a great wear resistance property as molecular links between the metal surface and natural ethers are much stronger than the adhesion net forces between mineral oils and the metal surface.

Depending on their viscosity, vegetable oils are based on natural or complex ethers. In contrast to mineral oil hydrocarbon molecules, the molecules of natural fatty acids are polar. This fact gives certain results. A high lubricating property and, consequently, an increased cutting tool durability is due to the difference between the vegetable oil and mineral oil molecular structures: vegetable oil molecules serve as small magnets collecting

\footnotetext{
${ }^{*}$ Corresponding author: rus.dzhemalyadinov@mail.ru
} 
at one end on the tool surface and forming a compact dense lubricating film (Fig. 1) thus providing for a high resistance towards external loads [3].

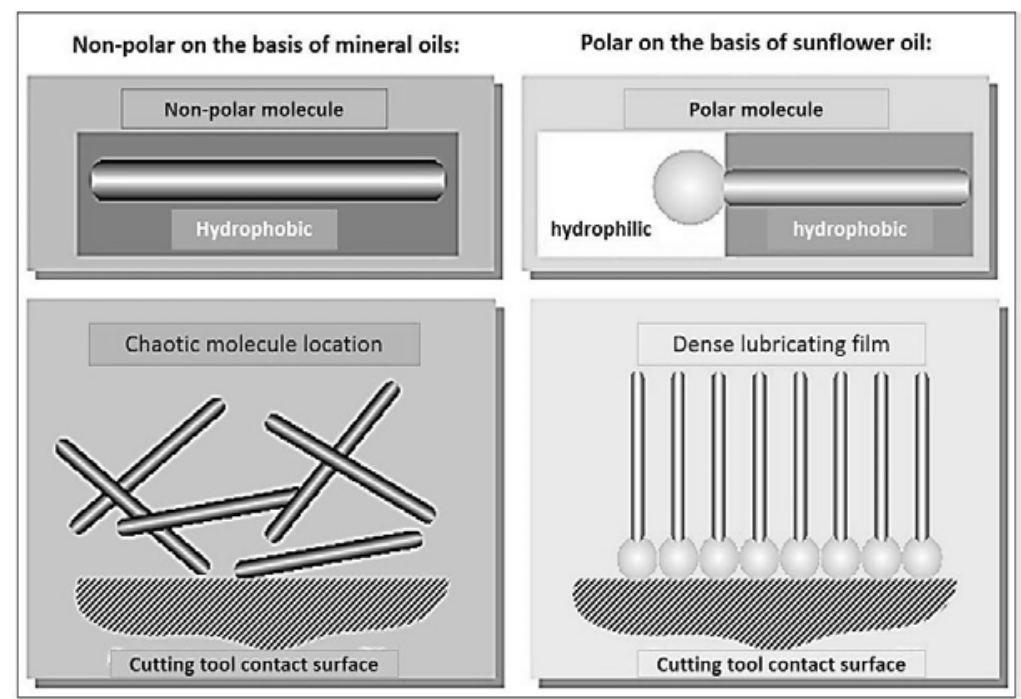

Fig. 1. Schematic layout of polar molecules forming a lubricating film on the tool surface.

Vegetable oil industrial introduction was facilitated by the development of various MQL technology options, with the feed of oils in the form of aerosol with the consumption rate at the level $10 \ldots 30 \mathrm{ml} / \mathrm{h}$ [4-6]. One of the widely applied options is presented in Fig. 2.

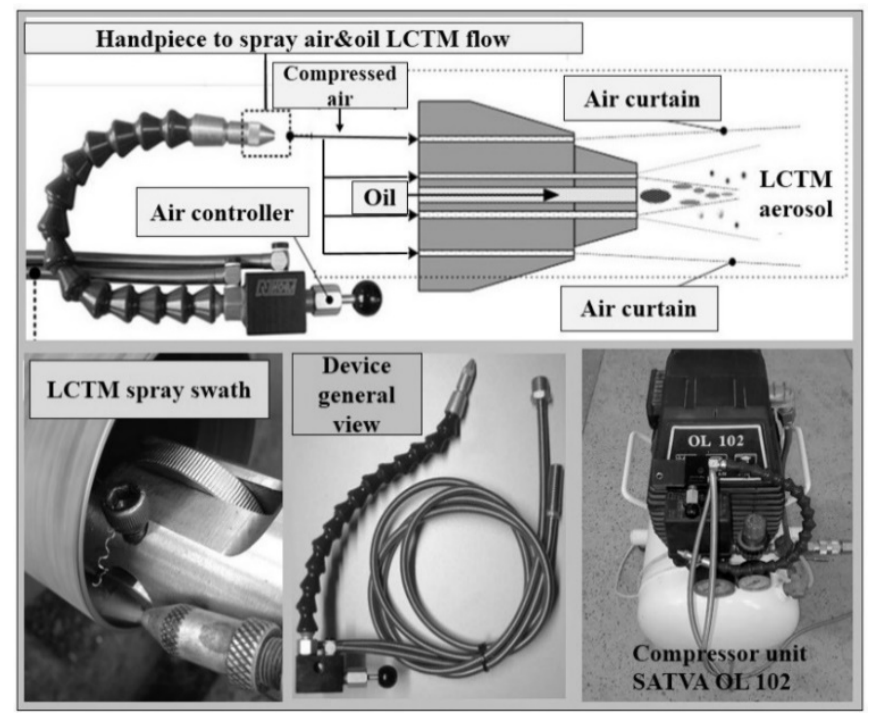

Fig. 2. The general view of the MQL feed scheme on the basis of the dosing device Noga Minicool.

The research showing how vegetable oils and animal fats improve the contact and volumetric process indicators are provided in Fig. 3-8. The tests were conducted at the treatment of specially selected materials different in material properties: highly deformed, non-oxidizing (slowly oxidizing) steel AISI 321 and high-tensile chemically active titanium alloy BT22. The cutting modes were selected to provide for the equal temperature of $200^{\circ} \mathrm{C}$ 
$\left( \pm 5^{\circ}\right)$ at the treatment of both materials. The cutting conditions are measured with the help of the dynamometer, UDM model M-30-3-6k, the dimensions of plastic - Lp and elasticplastic Le were controlled using the microscope IMIL $150 \times 75$, chip shrinkage was determined by the equation [7]

$$
K=\frac{1000 \cdot Q}{s \cdot t \cdot \rho}
$$

$\mathrm{Q}$ - chip weight, $\mathrm{t}$ and $\mathrm{s}$ - width and thickness of the layer being cut, $\rho$ - treated material density.

As a cutting tool, the authors applied a straight turning tool with HSS indexable inserts $\left(\gamma=0^{0}, \alpha=12^{0}, \varphi=\varphi_{1}=45^{0}, r=0,4 \mathrm{MM}, H R 63 \ldots 64\right)$, the oils are fed with the MQL method and the consumption rate $15 \mathrm{ml} / \mathrm{h}$.

\section{Statement of the main material}

The obtained data provided the answer for the key question - natural origin oils, fed with the rate 2-3 times lower comparing with the mineral oil consumption rate, influence cutting in the same way as the mineral ones, fed both with ordinary flooding and the MQL method, in terms of their main indicators.

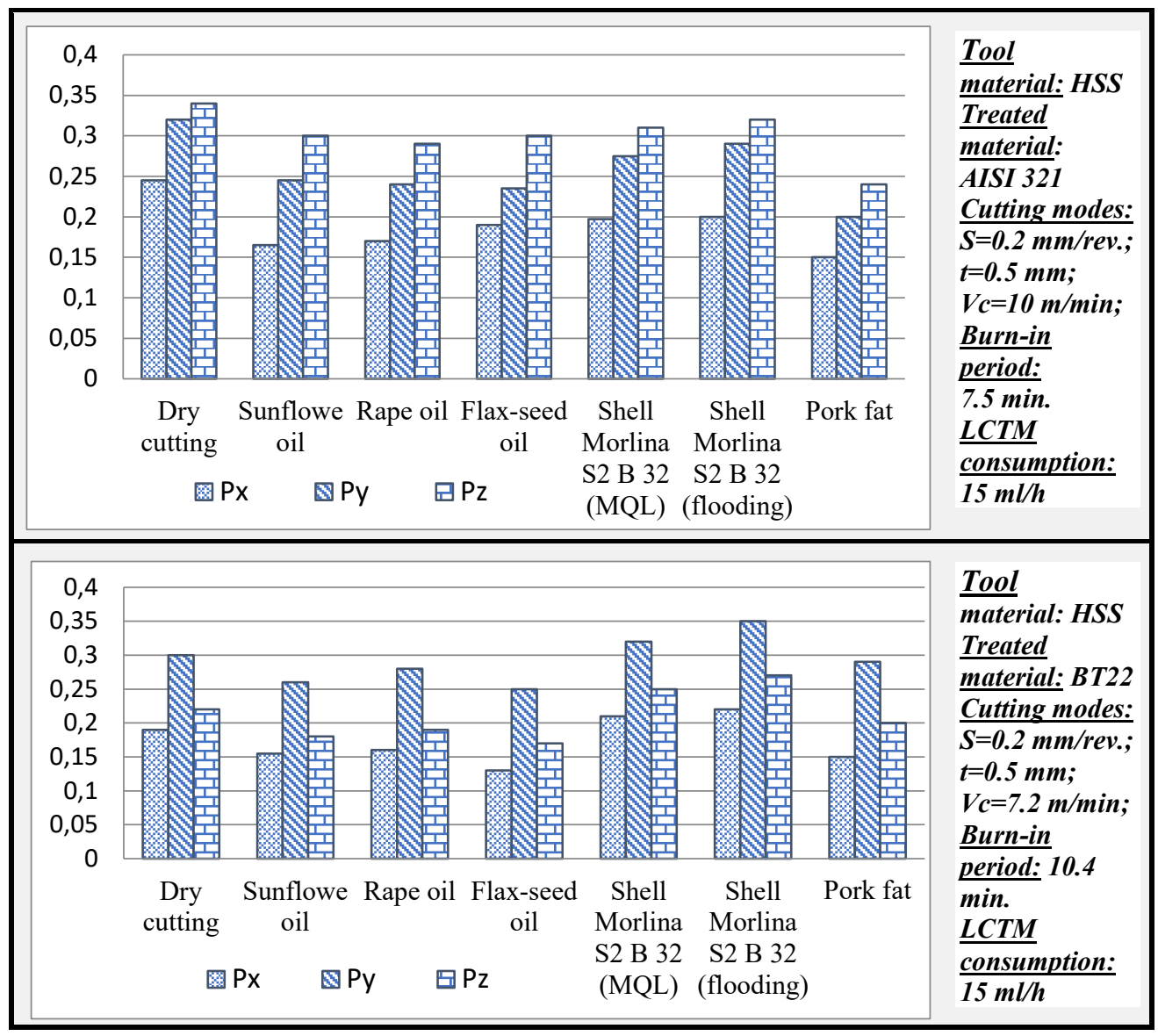

Fig. 3. Natural origin oil influence on cutting forces. 
However, there are significant advantages of vegetable and animal fats application at the treatment of materials different in their properties.

At the cutting of steel AISI 321 the following is observed:

1. Cutting forces components (Fig. 3) are virtually equal and are only slightly different from such components at "dry" cutting. The exception - pork fat decreasing the force Px by $25 \%$, which, presumable, is the result of the $3.5 \ldots 5.0$ times decreased plastic contact length comparing with "dry" treatment and the mineral oil feed Lp (Fig. 4).

2. Argon cutting (Fig.5) demonstrates the highest shrinkage $\mathrm{K}$ values which, supposedly, is connected with the intensification of adhesion processes and decrease of chemical process intensity in the contact area.

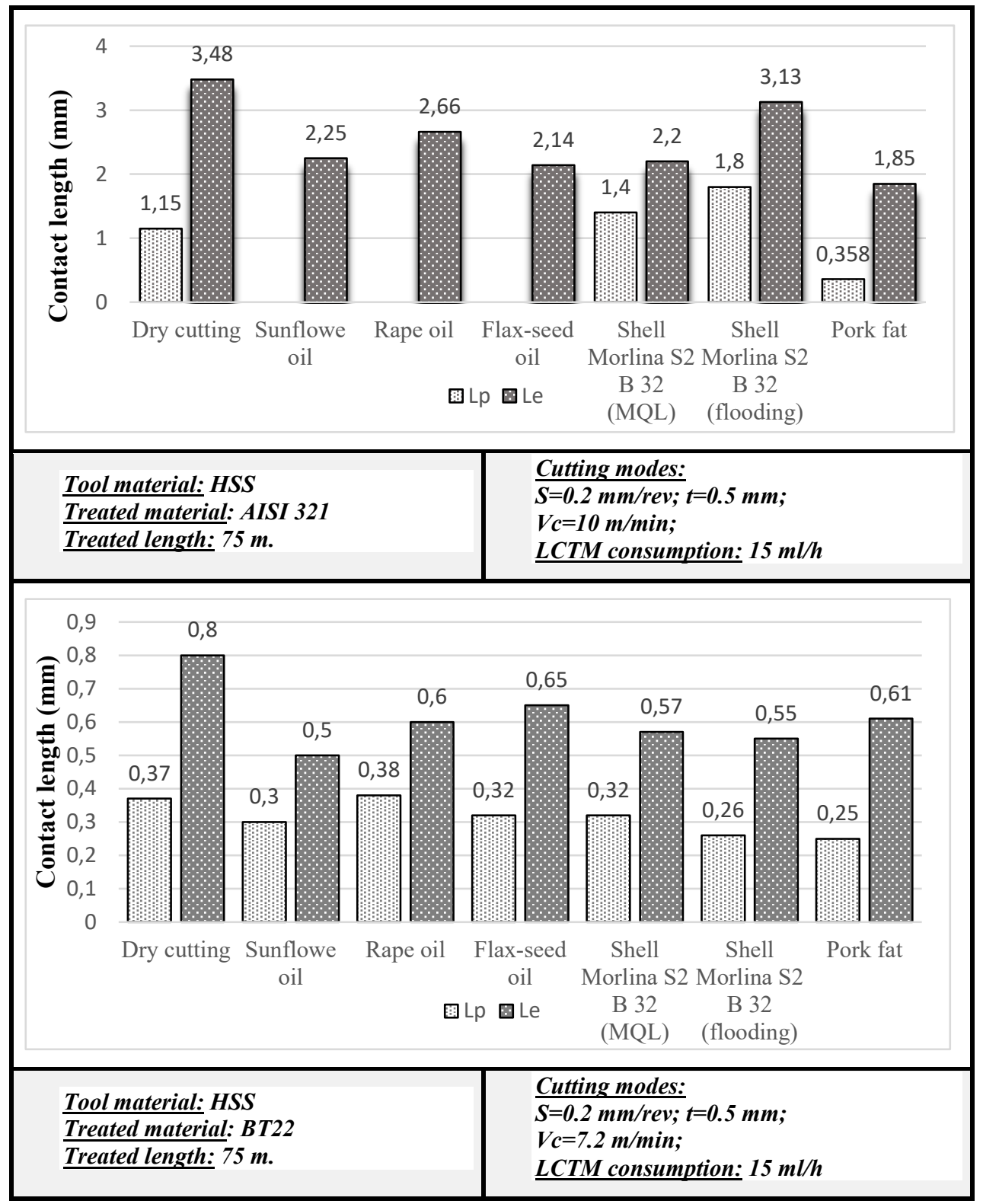

Fig. 4. Influence of natural origin oils on the plastic\&elastic and plastic contact length (Le, Lp). 
3. The increased values of the shrinkage factor $\mathrm{K}$ during the cutting initial period stabilize in the course of time (Fig. 6...8), which sets off the manifestation of their lubricating functions.

4. $\mathrm{Gas}\left(\mathrm{O}_{2}, \mathrm{Ar}\right.$, air) introduction into various vegetable oils has virtually no influence on the volumetric deformations (shrinkage $\mathrm{K}$ ).

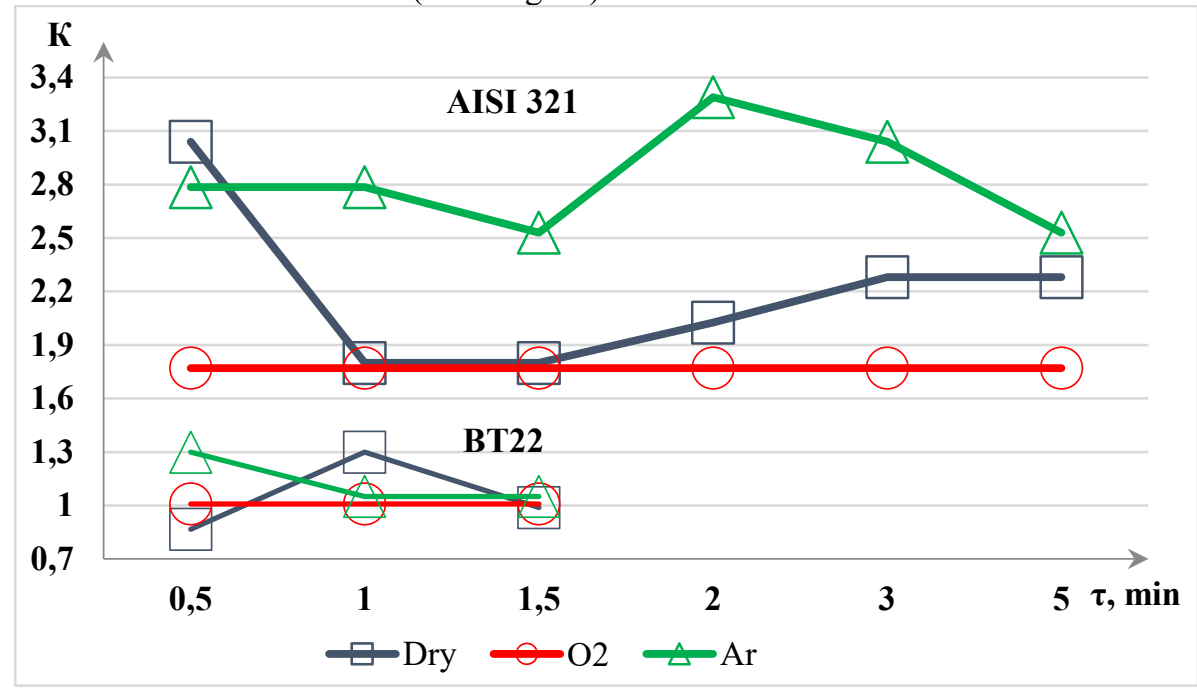

Fig. 5. Chip shrinkage at the treatment of steel AISI 321 and BT22 in the environment of various gases.

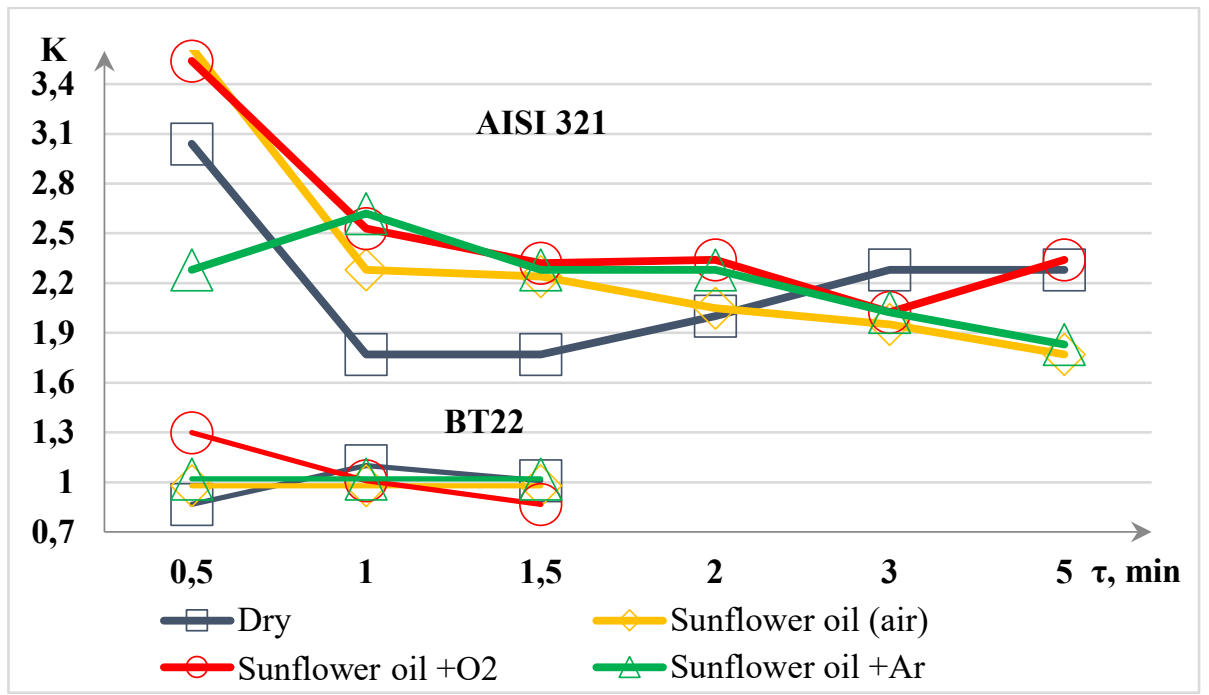

Fig. 6. Chip shrinkage at the treatment of steel AISI 321 and BT22 in the mixtures of sunflower oil with various gases

The cutting of the alloy VT22 is characterized by the following peculiarities:

1. There are shrinkage values with the factor $\mathrm{K}<1$ (Fig. 5,6,7,8) attributed to oil blowing off with $\mathrm{O} 2$ and nitrogen-containing $(73 \%)$ air. This emphasizes the influence of oxygen and nitrogen at the crystalline (expanding the grid parameters) level. At the application of pure oxygen, the shrinkage values are the lowest and close to one $(\mathrm{K}=1.008)$ 
which, presumably, is connected with some compensation at the shift with the crystalline grid expansion.

2. The mixtures "Rape-seed oil +Ar", "Flax-seed oil +Ar" stipulate for the highest shrinkage K (Fig. 7, 8) which, apparently, makes their blocking action manifest themselves at the entry into the oxygen cutting area and air nitrogen.

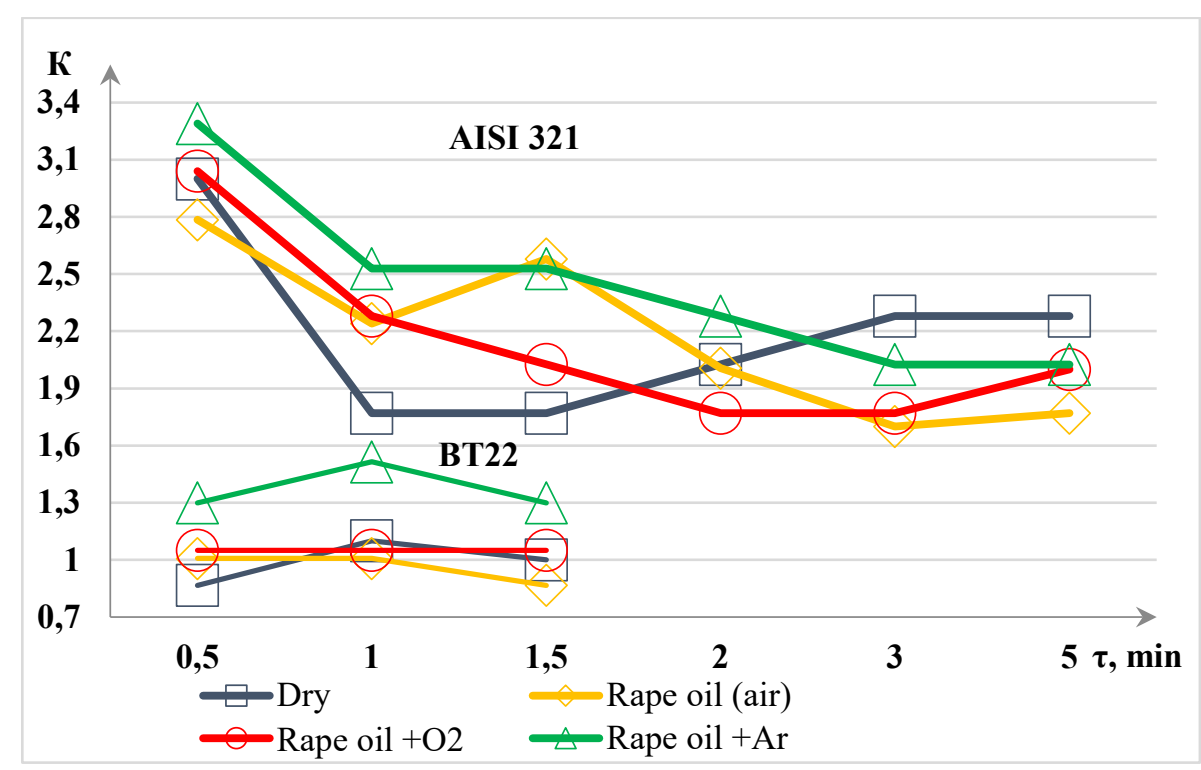

Fig. 7. Chip shrinkage at the treatment of steel AISI 321 and BT22 in the mixtures of rape oil with various gases.

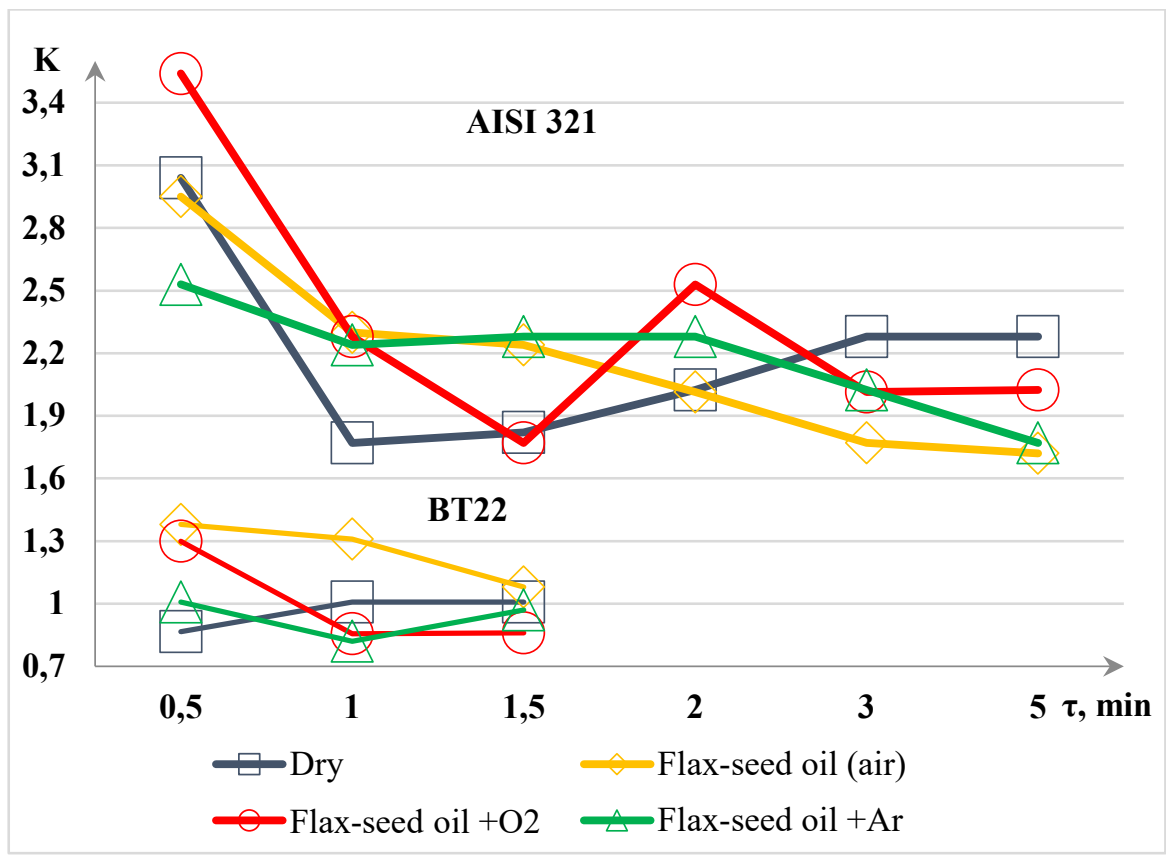

Fig. 8. Chip shrinkage at the treatment of steel AISI 321 and BT22 in the mixtures of flax-seed oil with various gases. 


\section{Conclusion}

1. Vegetable and animal oils fed by the MQL method influence the cutting indicators (both contact and volumetric) in the same way as mineral oils do. Light lubrication technique, which significantly reduces lubricant consumption, does not deteriorate the effectiveness of plant oils and ensures the required surface quality;

2. The MQL technology facilitates oil feed in combination with various gases into the cutting area, which provides for new opportunities in terms of selective and differential approach to the LCTM choice depending on the properties of treated and tool materials and cutting modes.

3. The presented data reflect the aggregate manifestation of those processes which take place in presence of increased voltages and temperatures and their gradient ratios, the concentrations of controlling elements and crystalline structure defects representing a complex set of physical\&chemical phenomena.

4. LCTM influence all these processes while natural origin oils having an increased lubricating property and containing surface-active substances (up to $70 \ldots 80 \%$ ) predetermines their depth of penetration into the contact gap and pre-destruction areas at the atomic and dislocation level.

\section{References}

1. A.S. Vereshchaka, A.K. Kirillov, A.A. Vereshchaka, O.Yu. Khaustova, Yu.I. Bublikov, Technological system of environmentally safe cutting for turning, News of Kabardino-Balkarian State University. Vol. №5. pp.20-22, (2014)

2. Ch. Yakubov, R. Dzhemalyadinov, The impact of technological liquids on the power features and quality of processed surface drilling in various construction materials, Scientific notes of the Crimean engineering and pedagogical University. Vol. №1(51) Technical Sciences. pp.132-137, (2016)

3. Ch.F. Yakubov LCTM strengthening action at metal cutting. (Simferopol, 2008)

4. A.I. Aliev, Scientific notes of the Crimean engineering and pedagogical University. Vol. 27, Technical Sciences, pp.42-46, (2011)

5. I.P. Chubb, I. Billenhen, Cooted cutting tools a study of wear mexanisms in high speed mashing Vol. №2. pp.283-293, (1980)

6. V.T. Protsishin, O.A. Mishchuk, M.A. Nyrkov, A.V. Bogaychuk, A.N. Ermakov, A.I. Aliev, Tribological Behaviour of Lubrication-Cooling Technological Surroundings and the Procedure of Their Measurement, Equipment and Tools for Professionals, №1. - pp. 54-58, (2007)

7. M.F. Poletika, Theory of cutting: P.1: Mechanics of the cutting process (Tomsk: Tomsk polytechnic university, 2001) 